\title{
What is the employment potential of a lean platform? The case of Dutch self-employed service professionals
}

\author{
Paul Jonker-Hoffrén \\ Work Research Center, Tampere University, Tampere, Finland
}

\begin{abstract}
Purpose - The purpose of this article is to study what platform-related user factors influence the employment potential of a lean platform for self-employed professionals.

Design/methodology/approach - The article employs the system data of a Dutch platform firm, which include consumers looking for painters $(N=17,224)$ and self-employed painters $(N=1,752)$ who pursue client acquisition by submitting proposals $(N=101,974)$. This data is analysed using non-parametric tests.

Findings - Study of this platform shows that the platform functions as a channel of acquisition for selfemployed professionals. This lean platform enables matching of information of supply and demand, thereby facilitating processes of acquisition. The number of competitors, distance to a potential job and non-standard proposals are statistically significant factors that influence whether a consumer is interested in a proposal. Effect sizes are very small.

Research limitations/implications - This platform is a two-way market for information about service jobs, which excludes a price setting mechanism. The findings of this study cannot be generalized to other forms of platforms.

Practical implications - The market for service professionals is very local; therefore, the platform firm may alter the algorithm to accommodate this. Self-employed professionals should approach using the platform in the same way as normal forms of acquisition.

Social implications - This particular type of two-sided market is an extension of regular forms of acquisition by creating "weak ties" through the platform.

Originality/value - The article uses a unique data set to study the impact and limitations of digitalization of the (labour) market for service professionals.
\end{abstract}

Keywords Self-employment, Digital economy, Service professionals, Employment, Two-sided labour market Paper type Research paper

\section{Introduction}

Since the beginning of the 2000s, the so-called platform economy has emerged. It has found application in many fields, from transportation (Uber and Lyft) to translation (Lionbridge) to microtasks, such as with Amazon's Mechanical Turk. Other, more demanding work can also be performed through platforms such as Upwork. Although the precise employment status of platform workers is often an issue of contention, in some cases platforms function as a kind of marketplace where self-employed professionals can apply for tasks or jobs. For self-employed

(C) Paul Jonker-Hoffr. Published by Emerald Publishing Limited. This article is published under the Creative Commons Attribution (CC BY 4.0) licence. Anyone may reproduce, distribute, translate and create derivative works of this article (for both commercial and non-commercial purposes), subject to full attribution to the original publication and authors. The full terms of this licence may be seen at http:// creativecommons.org/licences/by/4.0/legalcode

The study was financed by a post-doctoral research grant from the Academy of Finland (decision \#307925). The authors would like to express gratitude to colleagues from the Work Research Centre of Tampere University for the many fruitful discussions about platform work and methodological issues of this study. Furthermore, the authors would like to thank the editors of this special issue for their efforts, as well as the two anonymous referees for their comments, suggestions and criticisms.

Employment potential of a lean platform

Received 30 January 2019 Revised 25 October 2019 5 December 2019 24 March 2020 14 April 2020 Accepted 23 April 2020 
IJM

42,2

\section{6}

workers, a platform can be a valuable source of information on available work. This article analyses platform work through the system data of a Dutch platform firm which operates in the market for professional services, such as TaskRabbit or HomeAdvisor. The platform firm aims to bring together consumers who need services and self-employed professionals providing these services. This case discusses self-employed indoor painters. They can be active on the platform once the platform firm has verified their legitimate status through such methods as tax number and Chamber of Commerce registration. In this sense, they and the platform firm are embedded in normal labour and company law.

A platform firm can have several intrinsic functions. As Langley and Leyshon (2017) argue, there are two main aspects: practices of intermediation and processes of capitalization. The former aspect points to the ways platforms (inter)mediate in "normal" economic relationships, and the latter aspect refers to the processes that enable platform firms to generate value from the latter practices. This Dutch platform exhibits these traits: it intermediates by providing information to consumers and professionals, and it bases its revenue model on matchmaking. For self-employed house painters, this platform provides a readily available network, through which it is possible to find jobs. Commonly, acquisition of clients happens through marketing and use of networks (Granovetter, 1973). This platform allows self-employed painters to engage in direct marketing to potential clients, which have expressed a need for services available through the platform. When these painters use the platform to respond to requests, their activity generates the data analysed in this article. For example, responding to a request generates the value of the variable "distance to request". The proposal he or she writes generates the value for the variable on proposal length. Furthermore, activity on the platform also determines the number of competitors for a request. They are variables that operate in the process of customer acquisition on the platform by the self-employed professional. The research question of this study is: what platform variables influence a higher employment potential for self-employed painters?

This Dutch platform aims to reduce information friction about employment possibilities for self-employed painters, but in doing so, it also capitalizes on its role of "information matchmaker" (Agrawal et al., 2015). This matchmaking of information could be an important social function of a platform in a period with exceptionally tight labour market conditions, especially in the construction sector. Indeed, the Employee Insurance Agency (Uitvoeringsinstituut Werknemersverzekeringen, UVW, 2018) has signalled that selfemployment and smart networks are potential solutions to labour market shortages. The Netherlands has experienced labour shortages in some sectors since at least 2016, but the construction sector suffers particularly (UWV, 2018; see also EURES, 2019). The economic circumstances of the sector are relevant, because the data used in the article are from the year 2017. The Economic Institute for the Construction Sector (EIB, Economisch Instituut voor de Bouw; EIB, 2017) states that self-employed workers in this sector represent a highly flexible part of employment. EIB (2017) also shows that painters have suffered from the economic crisis between 2010 and 2016. This crisis is connected to current labour shortages, as during the crisis many experienced painters left the sector, retired or took occupational disability allowance (EIB, 2017, p. 15). For many construction occupations, such as painters, a great change has occurred: more painters are currently self-employed than party to an employment contract (EIB, 2017, p. 29). At the same time, painters are a leading profession in occupational disability statistics, and from 2013 to 2015 roughly half of the employees in the painting business became unemployed (EIB, 2017, p. 45).

House painters are a very common profession in the Netherlands among the self-employed in the construction sector. Painters are a technical profession, meaning they rely on personal skills, need very little capital and can do work for either consumers or on a contract for another firm. The construction sector in the Netherland provides around $6 \%$ of total employment (EIB, 2017). There are around 30,000 painters in the Netherlands. 
In sum, self-employed painters in the Netherlands are typical representatives of the construction sector. The economic situation in 2017 was highly favourable for them, considering the labour shortage and high demand for painters. Furthermore, it is expected that structural factors will see the growth in the share of self-employment in the construction sector reach its ceiling soon (EIB, 2017, p. 11). For example, the self-employed cannot take on bigger jobs unless they organize themselves in temporary coalitions or grow their firms.

Although the economic context in 2017 was favourable to painters, it is also clear there nonetheless may be labour market mismatches. Consumers may not find a good painter through their own networks and self-employed painters may also have limited resources to acquire information about new jobs. Platforms, such as the one analysed here, may be a solution by connecting information about supply and demand (Azevedo and Leshno, 2016). Less is known about whether the platform provides more employment possibilities for selfemployed workers and if their behaviour on the platform is related to this. In what ways does a platform provide employment possibilities? The aim of this paper is to provide some tentative answers to this issue.

Section 2 contains an overview of the literature on the platform economy: what platforms are, what they do and how they have developed. Where relevant, examples from the Netherlands are given. Based on this overview, research gaps in the theory and empirical study of platform work are identified, and research questions formulated. Section 3 introduces the data and the platform firm. Since the article uses system data instead of data collected specifically for this research, the limitations of the data and the specific challenges of the use of big data will be highlighted. Section 4 contains an analysis of the system data, which also highlights the value of these kind of data, while section 5 contains discussion and conclusions.

\section{Platforms: forms, technology and the labour market}

Florisson and Mandl (2018), Drahokoupil and Fabo (2016) and Dekker (2018) provide wideranging overviews of the various aspects involved. This section nonetheless highlights a few main issues that inform the research questions of this article. These issues are the historical development of the platform economy, especially in the context of technology; the relationship between platform work and the labour market; various forms of platforms and the relationship between organization of work and flexibility.

\subsection{Historical development of the platform economy}

Platforms have emerged since the 1990s. Schor and Attwood-Charles (2017) and Schor and Fitzmaurice (2015) discuss the development of the platform economy, in particular when defined as the sharing economy. Schor and Fitzmaurice (2015) date the emergence of the concept of sharing economy to 2008 and connect this to the economic crisis of 2008. Nonetheless, platforms as a model of organization existed already, for example, in the form of "time banks". Time banks are "a type of community currency which rewards people in time credits for the work they put into their neighborhoods" (Seyfang, 2004). Time banks function as a market for work, in which one is paid in time units rather than money. Other non-profit platforms have existed as well, since the second half of the 1990s, as Schor and AttwoodCharles (2017) argue. Stanford (2017) situates the development of digital platform work in an even longer historical perspective, arguing that what digital platforms do essentially existed already in Europe in the time of merchant capitalism, around the 16th century, albeit in a nondigital form.

The platform economy really took off around the late 2000s with firms such as Uber, Airbnb and TaskRabbit. Firms such as ServiceMagic and Dutch Marktplaats.nl and
Employment potential of a lean platform 
IJM

42,2

\section{8}

Thuisbezorgd.nl were early movers, founded in the late 1990s and early 2000s (Frenken and Straathof, 2015). These firms had developed into major players by the mid-2000s. The platform firm studied in this article is also one of the older ones, founded in the mid-2000s. In terms of employment, the platform economy is still small, but there are many sectors in the Netherlands where platforms enable gig work, for both self-employed workers and "casual workers". Among the typical casual work gigs are domestic work, personal transport, food delivery and various microtasks (ter Weel et al., 2018).

\subsection{Relation between platform work and the labour market}

The platform economy is enabled by developments in ICT and resulting innovations in business organization (Srnicek, 2017; Castells, 2010). Platforms, using ICT and the mechanism of the "two-sided market" can act as a labour market mechanism in a variety of ways. Successful platforms connect supply and demand and, in that way, add to economic growth. Platforms may influence the organization of the labour market too, as work is not necessarily bound to a specific location (Castells, 2010, p. 121; Evans, 2003; Evans and Schmalensee, 2007). ICT allows production processes to be divided into pieces and performed non-locally. Friedman (2014) and Evans and Wurster (1999) show that the rise of the platform economy (and/or gig economy) is not only related to technological innovations but relates to competitive pressures on firms and strategy as well.

Platforms can also shape labour allocation in the labour market (Langley and Leyshon, 2017; Schor and Attwood-Charles, 2017). Platforms fulfil the function of connecting labour supply and demand (Friedman, 2014; Codagnone et al., 2016; Autor 2001, 2013). Speed is also a clear advantage of platforms as a labour market mechanism: Fieseler et al. (2019) write of fluid labour markets and "spot markets". Also, online reputation is relevant (Gandini et al., 2016). Importantly, Kingsley et al. (2015) argue that platforms can have significant effects on labour market inequality through friction and power asymmetry.

\subsection{Forms of platforms}

A core aspect of platforms is their form. Following seminal research by Rochet and Tirole (2003), all platforms seem to have the form of "two-sided" or "multi-sided" markets (Autor 2001, 2013). Kenney and Zysman (2016) provide a non-technical introduction to these markets. de Reuver et al. (2018) argue that scholars should be precise in their discussion of platforms, because there is a great variety of platforms with different boundaries, units of analysis and technical scope (see also Drahokoupil and Fabo, 2016). There is a variety of definitions of the platform and/or gig economy. Balaram et al. (2017) define the gig economy as the "trend of using online platforms to find small jobs, sometimes completed immediately after request". They distinguish between asset-based platforms (e.g. Airbnb) and labourbased platforms (Uber, TaskRabbit). Another division into virtual and non-virtual work is possible (e.g. Amazon's Mechanical Turk vs Uber), as well as a division based on the work itself: work for sales, marketing and IT professionals (Upwork) and physical jobs (TaskRabbit) (see de Stefano, 2016).

\subsection{Flexibility and organization of work}

Srnicek (2017) makes a different distinction, which relates to the organization of work and production rather than the product of the platform. He argues that there are advertising platforms (e.g. Google, Craigslist) and cloud platforms (Amazon Web Services). Furthermore, there are industrial platforms, which use Internet to optimize production (industrial IoT), product platforms, where the company owns the assets (or rights) it rents out (Zipcar or Spotify) and lean platforms, which are "lean" because they own only the platform and the data 
analytics used with/on the platform (e.g. Uber, TaskRabbit or Airbnb). Schor and Fitzmaurice (2015) make a distinction between platforms that enable sharing of "idle assets" and people's services.

Such platforms "extend" the labour market, rather than organize work in a different way. An issue which often comes up in relation to this kind of platform is the employment relationship (Florisson and Mandl, 2018), which can be a proper employment contract or a rather more diffuse form (see, e.g. Cappelli and Keller, 2013). For the platform in this study, this is not a consideration: the "service providers" are self-employed painters. This lean platform does not contain a price-setting mechanism, which is an important difference to platforms such as TaskRabbit, which do have price-setting mechanisms. The advantage for the platform is that it will not become embroiled in legal battles over the exact form of employment relationship. As a lean platform, the platform firm itself takes a minimally active role in connecting the two sides of the market, especially since a price-setting mechanism within the platform is also missing.

There is an emerging literature on "Labour as a Service", which notes that issues of power asymmetry and uncertainty are common on platforms, in particular for self-employed entrepreneurs (Cutolo and Kenny, 2019). The EU-wide COLLEEM survey shows that people who are active on platforms as a source of employment are often also active as self-employed entrepreneurs (Urzì Brancati et al., 2020, p. 52). Farrell et al. (2018) show for the United States that non-transport platform work accounts for a small share of total income. This implies that most of the income comes from other sources. The main research gap this article identifies is how such a platform functions for its users and how users could potentially influence the effectiveness of the platform for their aims.

\section{Data and methods}

This article uses the system data of a Dutch platform firm, which was pulled from the firm's database and delivered as Excel files. The data consisted of three parts: data on the professionals (painters), data on the consumer's job requests and the proposals made by the professionals. Combining the data using relative keys as if it were a database (in this case: the proposal IDs) resulted in a single data set with job requests $(N=17,224)$, professionals looking for work $(N=1,752)$ and proposals $(N=101,974)$. The empirical material can be classified as Big Data in the sense of Burrows and Savage (2014): "data generated as a digital by-product of routine transactions", in this case between consumers and self-employed painters active on the platform. It is what Tinati et al. (2014) call data on what people do "in the wild", without interference from researchers and observed without the prism of survey or interview questions. The data bear the marks of a database: they feature time stamps for requests and proposals, geolocation information for requests and proposals and many fields that indicate the content of the job request. The data on the self-employed painters used in this study accounts for around $6 \%$ of professional Dutch painters.

For this article, the data have been recoded to be able to track the transition from one proposal status to the other. To be able to include information about the proposal, variables have been created to identify the character length of proposals, whether it is a standard proposal for that professional and how many standard proposals he or she has submitted during his or her time on the platform.

The empirical material of this study is therefore a-typical. The challenge is to apply data from a database setting to social science research (Chen et al., 2012). Contrary to many other studies on self-employment and platforms, this study does not employ survey data. Surveys are a common method in labour market research for obvious reasons: they provide a wealth of data and enable researchers to employ established statistical techniques, therefore enhancing reproducibility and comparability with other studies. Furthermore, survey design enables a
Employment potential of a lean platform 
IJM

42,2

310

certain standardization, thereby ensuring long-term comparability of data. Surveys also have drawbacks. As shown here, the data show person-level information over a dense period, which would be impossible to extract from a survey. Also, surveys may have issues of validity, under- or over-reporting and social desirability (Belli et al., 1999). Furthermore, surveys may not be able to provide reliable data on relatively marginal issues.

The analysis of big data can be similar to "normal" statistical analysis (Chen et al., 2012, p. 1175). Kitchin (2014) argues that a purely empirical approach to big data is misguided, as the data do not arise naturally. They are a result of the technology employed, such as the algorithm. Therefore, a big data analysis is not purely empirical but is grounded in the structures and processes that generated the data, which is why the platform of this study and the data structure are explained in some detail. The use of big data in this study should be seen as a digital case study. In this sense, the platform data is a snapshot of an open system with a certain institutional dimension: professionals can join, leave, be active or inactive, but the platform system shapes their behaviour.

Furthermore, Kitchin (2014) argues data are not in any way neutral, but contingent on how they were generated (see also Karpatne et al., 2017). Burrows and Savage (2014) also posit that the use of big data in sociology is a great methodological and epistemological challenge. They argue that most social science methodologies rely on "accounts of what happened", and big data, on the other hand, show what actually happened. They call this digital transactional data, which are the by-product of how people behave through interaction on digital media. As a result of these transactional data, social science using big data permits a more "granular" analysis of the "social" as well as more attention to outliers and cases (Burrows and Savage, 2014, p. 5). The analysis in this article is theory-driven in the sense that it aims to do justice to the way data are generated. This means that the links between variables are formed in part by the structure of the platform. This article aims to show these links and a tentative explanation. Thus, Burrows and Savage (2014) and Kitchin (2014) point to the benefits of big data analysis as specific case studies, provided the context and domain of the data are sufficiently included. The data of the platform thus represent the platform, its assumptions and its functioning (Kitchin, 2014).

\subsection{Data generation by the platform}

The platform firm has an important role in structuring the data (Kitchin, 2014), which is shown in Figures 1 and 2. A new job request is visible to all self-employed painters on the platform. The platform firm assigns a fee, based on approximate size, to the job, which the professional must pay if the consumer picks his or her proposal for further contact. This is the main process of capitalization for this platform firm. The algorithm of the platform allows a maximum of ten proposals per request. In theory, at least, the algorithm will limit the number of requests so that after a request is posted, responses must be quick to be included.

Professionals respond to a request by sending a proposal through the platform. A proposal often includes a statement of interest, indication of brands used by the entrepreneur, references to experience or earlier projects and contact information. Some proposals even contain requests to contact the entrepreneur directly, in order to circumvent the platform. This concludes phase 1 , the technical phase. The resulting data structure can be seen in Figure 2. In phase 1, the intermediation consists of the algorithm limiting the number of professionals per request and the determination of the proposal fee. Furthermore, the data on distance to the job request are generated each time a job request appears. Also, the number of competitors is generated in this phase through the actions of the self-employed painters. This is in practice what Kitchin (2014) refers to as the "situatedness" of the data.

In phase 2 , the consumer considers the proposals he or she received and selects the most promising proposal(s), or sometimes, none of them. It is in this phase that the proposal makes 
a difference. The professional's distance from the request also is important, as it represents a direct cost to the professional (car use) and an indirect cost to the consumer (transport costs are billed to the consumer). For the self-employed painter, there is risk in responding to any job request, because he or she might be liable to pay a fee without receiving the job. The consumer can consider the professional by looking at the review score, a grade from 0 to 10 . The consumer can also see other consumers' reviews of the same professional.

When the consumer selects a proposal, its status changes to "mutual interest", which means the professional must pay a fee (which ranges from $€ 6$ to $€ 52$ in the data). This is one instance where power asymmetries are clearest. With this status change, the professional will now be able to see the consumer's contact details, which allows phase 3 , the actual client acquisition, to start. The platform firm is no longer involved after phase 2: the professional will contact the consumer and they will negotiate the job. This is a typical characteristic of a lean platform. The consumer may indicate on the platform whether he or she hired a professional through the platform and leave a review, but the platform firm mentioned that few consumers bother to do this.

\subsection{Study variables}

This article can be seen as a digital case study, exploring the user factors influencing their employment potential within the context of the platform. Since the data originate from the database of the platform, many common variables used in social science are missing, such as age, sex and job experience (see also Gandomi and Haider, 2015). The platform data provide only a limited set of variables, which nonetheless are expected to influence the self-employed painters' employment possibilities through the platform. These variables are number of competitors, proposal length, distance to the job request and the standardization of the proposal.
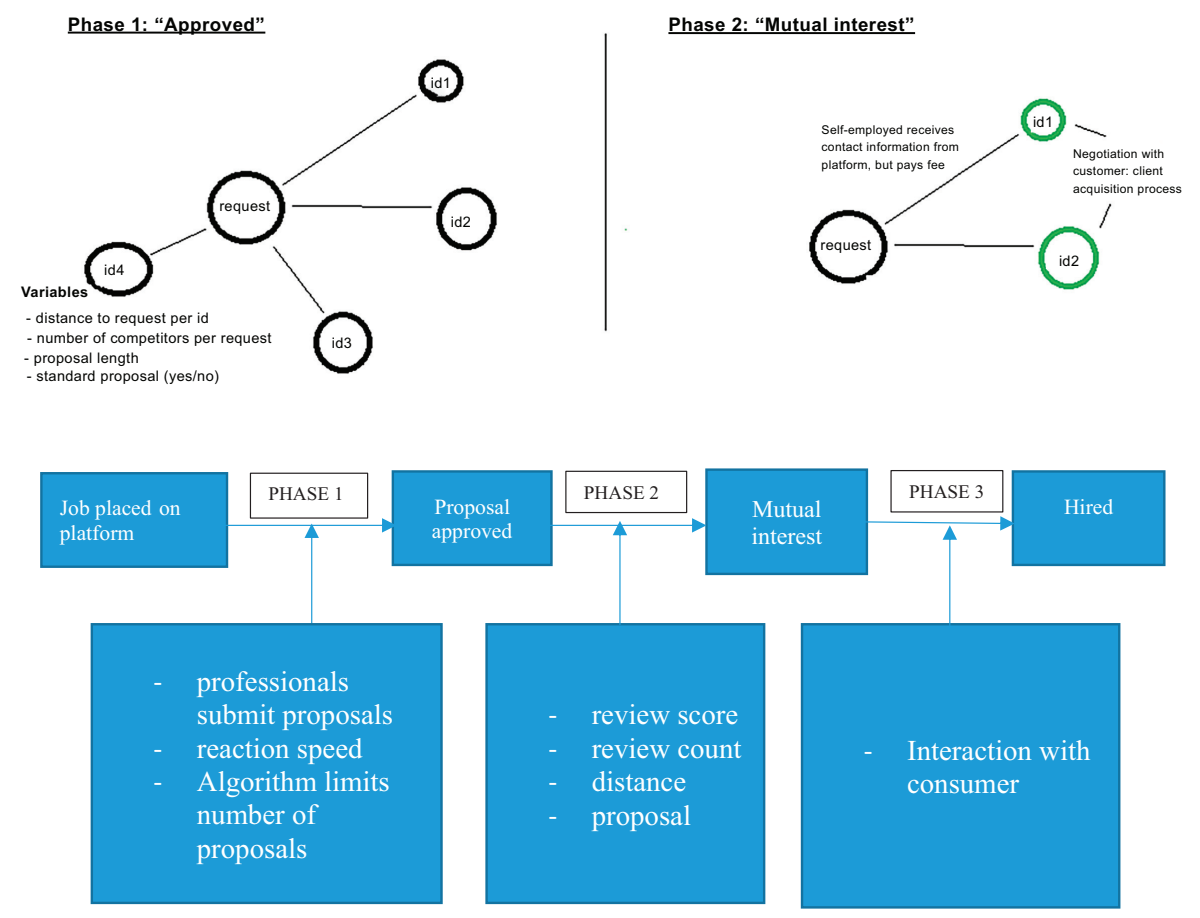

Figure 2.

The data structure of the platform data
Employment potential of a lean platform

Figure 1.

The platform conceptually professionals

reaction speed

Algorithm limits

number of

proposals review count

distance

proposal 
IJM

42,2

312

In the following analysis, it is assumed (following Dekker, 2018) that the self-employed painters are not primarily dependent on the platform for employment, but rather use it for new client acquisition. This fits with the economic context described earlier. There is a potential cost to using the platform, so it is assumed the painters will aim to write proposals for potential consumers that have the potential to seriously attract a consumer's attention. Qualitative analysis of the proposals is outside the scope of this article, but two proxy variables are used instead: whether a proposal is standardized (all potential consumers receive the same proposal) and the length of the proposal in characters. Self-employed painters, as entrepreneurs, would write a proposal specifically for the job request in question and that a longer proposal gives the consumer more information to base his or her decision on. Therefore, it is expected that self-employed painters who write non-standard, longer proposals would on average be more likely to achieve the mutual interest status. The expectation regarding distance to the request is that closer service professionals would be more likely to have a status change than those further away. The reasoning lies in the issue of transport cost: a gig further away entails greater fuel costs and (especially in the West of the Netherlands) costs in time (and traffic jams). It must be remembered that the distance to the request is dependent on the appearance of the request on the platform. Finally, it is reasonable to expect that there is a difference between the two groups regarding the number of competitors: although consumers may not find the professional they are looking for in all cases, a smaller number of competitors will, ceteris paribus, increase the possibilities that the consumer selects his or her proposal. Nonetheless, this is also a factor that comes into existence through the request and the behaviour of the self-employed painters themselves. Furthermore, it is a factor they are unaware of.

In the context of phase 1 of the platform, there are only two factors the self-employed painter can influence directly. The first is the length of the proposal and the second whether it is a standard proposal or not. The distance to the request as such cannot be influenced but based on the reasons stated earlier, it is sensible to assume that the painters select job requests that are relatively close. The number of competitors is a background factor. In this article, the focus is mainly on differences between two areas in the Netherlands, the Randstad metropolitan area and the rest of the country. The Randstad area consists of the provinces North and South Holland and Utrecht. This area is of significant economic importance for the Netherlands, since it includes the ports of Rotterdam and Amsterdam, the governmental seat of The Hague, Schiphol Airport, the financial centre of Amsterdam and the infrastructural hub of Utrecht. It is home to over $8 \mathrm{~m}$ people. The province in which a request appears is relevant, because the population density in the Randstad area is greater than elsewhere.

This means that both the supply of self-employed painters and the availability of job requests are greater than in other regions, which influences the average distance to requests and the number of competitors per request.

The employment potential of a lean platform for self-employed workers is in principle significant. Such a platform combines several traits, which enable employment potential, that is, successful client acquisition. The presence of demand for services is the main advantage, since knowledge of the needs of potential customers can enable precision acquisition. For selfemployed workers, the availability of knowledge about demand for their services is valuable, because this is knowledge that for most exists beyond the limits of word-of-mouth referrals. For self-employed workers it can also be beneficial to be active on a platform, which enables customer engagement behaviour (Van Doorn et al., 2010). In its most simple form, potential customers can read the reviews and review scores by other customers before contacting the service provider. In this way, the platform "amplifies" word-of-mouth referrals. When used in this way, the platform is an example of what Granovetter (1973) calls "weak ties". These weak ties may transfer information that is valuable to a person, but the information resides with people the first person does not know well. The self-employed worker can use other 
information available through the platform as well. It can be used to plan work, such as customer location, material needs and scheduling. In theory, a data-savvy gig worker could gauge trends in his/her field, in order to foster skills to match emerging developments.

Overall, we expect, in line with Codagnone et al. (2016, p. 44) and Cullen and Farronato (2015), that the potential to gain employment from this kind of platform is quite modest. The main reason is that a request for painter services is always a unique request for a particular situation. This means that there is a high theoretical potential for client acquisition through the platform, but on the other hand the platform introduces extra steps in this process. Consumers must fit their job into predefined categories and characteristics, while the selfemployed painters cannot realistically write a binding offer to the request on that basis alone. In a sense this is a logical consequence of this kind of lean platform, because for non-standard work it is difficult to include a (binding) price-setting mechanism within the platform.

\subsection{Methodology}

Preliminary analysis of the data included correlation tests (Kendall's tau), which indicated that there are very small, statistically significant correlations between the success rate of the self-employed painter on the platform and the variables described earlier. The success rate is the ratio of successful proposals per total attempts by a professional. The number of competitors and the distance to the request have a small, but negative correlation. The length of the proposal and standardization of the proposal have a near-zero, positive correlation. The self-employed painter's overall review score is also positively correlated with the success rate, but for practical purposes its value for the analysis is marginal.

The analysis of this article employs the Wilcoxon signed-rank test to compare scores of participants, but these scores come from the same participants. This ranking test is useful in this case, because the data violate the distributional assumptions of parametric tests (Field et al., 2012, p. 667). The platform data have a structure that makes it difficult to apply other methods: the same self-employed painters react to job requests in different locations and in different groups of competitors. Furthermore, correlations between the variables are rather weak.

The Wilcoxon signed-rank test compares the ranking of participants (in this case the selfemployed painters) based on a condition, in order to establish if there is a difference between the groups after an intervention. In the case of these data, the condition is "approved" or "mutual interest" and the intervention is the consumer selecting a proposal/proposals. The significance of the test as well as the effect size was calculated using R statistical software. Also, the median is reported.

\section{Results}

In this study, the employment potential of the platform for self-employed painters has been defined as a status change from "approved" to "mutual interest". This is the key change that happens within the platform, which enables the platform users to connect to potential customers. On this platform, as a form of labour market intermediation, consumers open the channel of acquisition for the self-employed. In this sense, the proposals the self-employed supply to service requests can be seen as a form of marketing.

Table 1 shows the total number of requests, the number of approved proposals, the number of mutually interesting proposals and the percentage of mutually interesting proposals of the total. These data are shown by province, because the provincial variance in both professionals and requests is great. The Randstad provinces (North and South Holland, Utrecht), North Brabant and Gelderland account for most requests and proposals. Furthermore, use of the platform is very urban: when plotting the requests on a map
Employment potential of a lean platform 
IJM

42,2

\section{4}

(Figure 3), one can clearly see the major cities in the less-populated provinces of the Netherlands.

There is a reputation effect of some kind visible in the data, although the review score cannot be included. The success rate of the self-employed painters tends to be around $15 \%$ on average in the data. Each professional has his or her own success rate trajectory, but professionals that have made more than 200 proposals show a success rate range of between 5 and $25 \%$. The longer the professional stays on the platform, the closer the cumulative success rate gets to $15 \%$. For shorter platform use, there is high variability in the success rate. Persistence is not necessarily rewarded, as each new request is a new competition situation, where the professionals are again on a level playing field and selection by the consumer is based on unknown factors. The median response time, which is less than $1.5 \mathrm{~h}$, confirms the need for quick responses. On the other hand, it is unclear why the painters stop using the platform at some point.

The main aim of this article is to investigate the various factors that influence the employment potential on the platform, especially the factors that platform users (the selfemployed) can influence. The results of the analysis are reported in Table 2 . The distance to the request differs significantly between proposals with approved status and ones labelled mutual interest. This means that proposals with a technically approved status are further away than those that are of mutual interest, but the difference is small. Both groups have many outliers, but the maximum value excluding outliers is in both cases around $100 \mathrm{~km}$. The median distance to an approved proposal is only $24.8 \mathrm{~km}$ and to a mutually interesting proposal even less. This result does, however, indicate that competition between painters is essentially local.

The number of competitors differs significantly between proposals with approved and mutual interest status. Statistically speaking, technically accepted proposals have more competitors than those that are "mutual interest", but again the effect size is small. This is a logical finding, but the professionals cannot know how many competitors there will be. According to the algorithm of the platform, there should be at most ten competitors. The use of non-standard proposal by users with approved status differed significantly from users with mutual interest status. This means that users with approved status use non-standard proposals

\begin{tabular}{lcccc}
\hline Province & Requests & Approved proposals & Mutual interest proposals & Mutual interest (\%) \\
\hline Randstad & & & & \\
Zuid-Holland & 6,445 & 23,691 & 4,079 & 14.7 \\
Noord-Holland & 6,235 & 23,150 & 4,242 & 15.5 \\
Utrecht & 3,076 & 11,266 & 1,864 & 14.2 \\
Other & & & & \\
Noord-Brabant & 3,135 & 11,357 & 1,786 & 13.6 \\
Gelderland & 2,190 & 6,566 & 1,253 & 16.0 \\
Overijssel & 932 & 2,211 & 546 & 19.8 \\
Flevoland & 824 & 2,349 & 529 & 18.4 \\
Limburg & 790 & 1,770 & 436 & 18.8 \\
Groningen & 489 & 1,467 & 334 & 17.5 \\
Friesland & 419 & 1,158 & 245 & 17.7 \\
Drenthe & 337 & 962 & 207 & 23.9 \\
Zeeland & 182 & 385 & 121 & 15.3 \\
Total & 25,054 & 86,332 & 15,642 & \\
Note(s): & 152 & &
\end{tabular}

Table 1.

Requests and proposals by province

Note(s): percentage is based on total approved proposals, which also includes the mutual interest cases, as they were initially also technically approved 

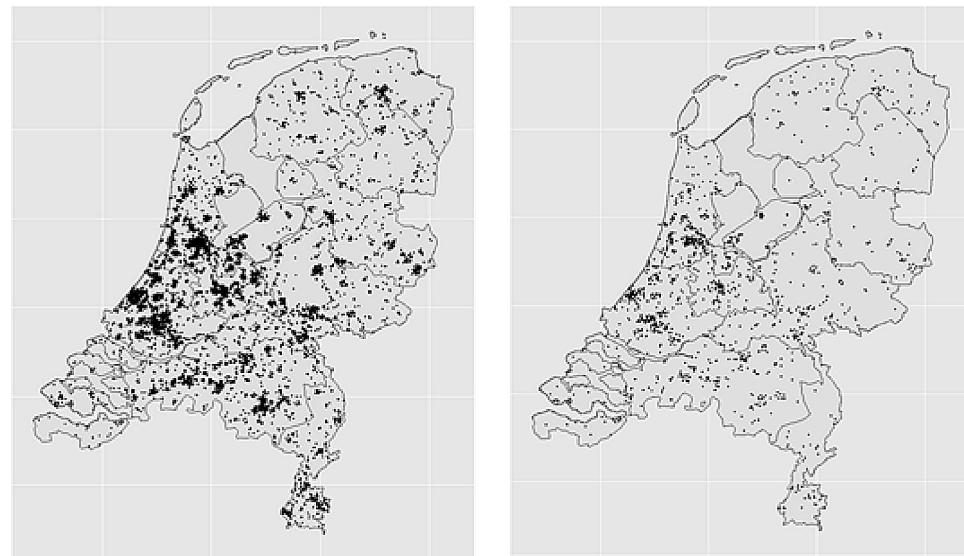

Employment potential of a lean platform

Figure 3.

Geographical spread of job requests (left) and service professionals (right)

\begin{tabular}{|c|c|c|c|c|c|}
\hline & $\begin{array}{c}\text { Median } \\
\text { (approved) }\end{array}$ & $\begin{array}{l}\text { Median (mutual } \\
\text { interest) }\end{array}$ & $\begin{array}{l}W-\text { test } \\
\text { statistic }^{\text {a }}\end{array}$ & $\begin{array}{c}\text { Effect size } \\
r\end{array}$ & \\
\hline Distance to request $(\mathrm{km})$ & 24.8 & 20.1 & $759,400,000^{* * *}$ & -0.078 & \\
\hline Number of competitors & 9 & 6 & $859,580,000^{* * * *}$ & $-\infty$ & \\
\hline $\begin{array}{l}\text { Standard proposal }(0=\text { TRUE, } \\
1=\text { FALSE })\end{array}$ & 1 & 1 & $694,260,000^{* * *}$ & -0.021 & \\
\hline Proposal length (characters) & 428 & 439 & $672,140,000$ & - & Results of Wilcoxon \\
\hline \multicolumn{5}{|c|}{ Note(s): (a): *** signifies statistic is significant at $p<0.01$} & signed-rank test \\
\hline
\end{tabular}

more often than those with mutual interest, but there is only a very small difference. This is a puzzling result. Visual inspection of the users with mutual interest status shows that within that group, differences between the two categories of proposal are smaller than with the approved status. It is possible that the proposals of the latter status are, qualitatively speaking, not very good, even they use non-standard proposals frequently. The length of the proposal, on the other hand, does not significantly differ between approved and mutual interest.

Figure 4 shows the density distribution of the distance to the job request (a), as well as the density distribution of the number of competitors (b), organized by region ("Randstad" and "Other"). This is shown for the "approved" and the "mutual interest" status. The figure shows that distance does matter. Furthermore, the figure shows that in the non-Randstad areas, the number of competitors is commonly less than ten, for the "mutual interest" status. Interestingly, it is clearly visible that in quite many cases, there are more than ten competitors. The platform company's data scientist supposed this is caused by a bug in the algorithm.

Above all, the earlier analysis shows that there are only small differences between the proposals that are technically accepted and those that attract the interest of the consumer, which can also be seen from the aforementioned figures. This is a relevant result, because it seems to indicate that in the context of the platform, it is not easy to get ahead of the competition.

\section{Discussion}

In this article, we studied the employment potential of a lean platform for self-employed painters. In theory the employment potential is quite big, because the platform enables a demand-driven form of customer acquisition. The platform user knows what jobs are 


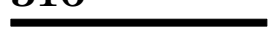

Figure 4.

Density distribution of (a) the distance to a proposal, and (b) number of competitors

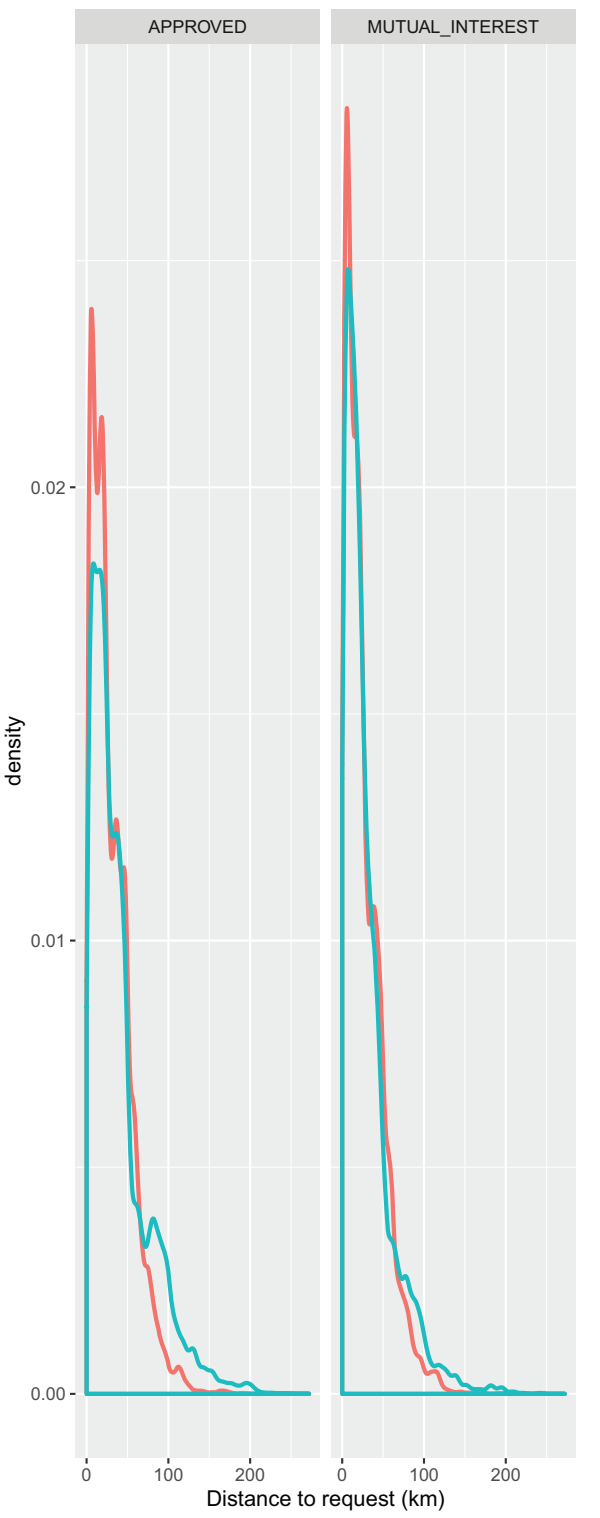

(a)

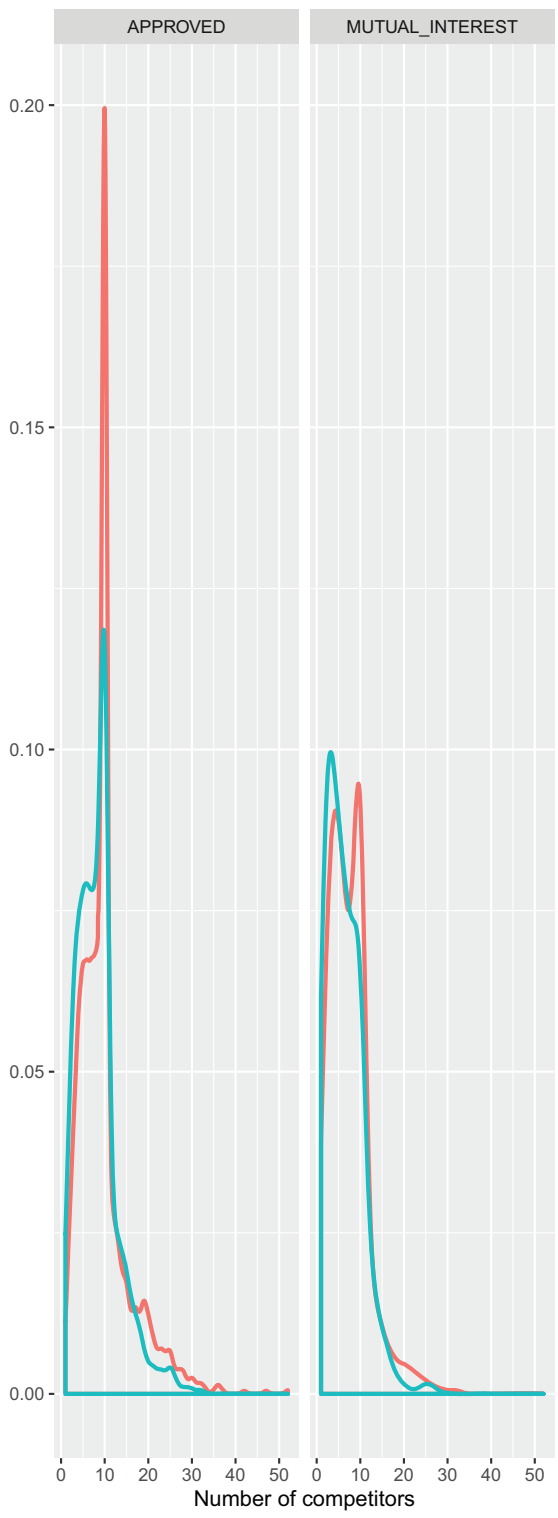

(b)

region $\square$ Randstad $\square$ Other

available, so he or she can use the information about job requests to his/her advantage to win the customer. Using the Wilcoxon signed-rank test we found that distance to the potential customer is a significant factor: self-employed painters that are closer are, on average, more likely to have a status change, which enables direct acquisition. In the current analysis, 
a non-standard proposal does not seem to improve the possibility to be selected by the consumer. This is a factor that should be further researched using more nuanced measures, for example, through text-mining the proposals. One factor, which the platform user cannot influence, is the number of competitors for a specific request. In the non-Randstad provinces there are less competitors, which means that the platform could function better as a channel of customer acquisition in these provinces than in the Randstad provinces.

For research on self-employment, it is interesting to see that these self-employed painters look for jobs very locally. This is perhaps not surprising by itself, but it stands in conflict with the discussion of Kalleberg and Dunn (2016) on the possibilities of platform work for "spatialization", or opening up the labour market for workers that due to their location would have only access to a very local pool of work. This platform shows that, while there are professionals who seek work nationwide, self-employed painters aim for local client acquisition. Furthermore, since this platform is not in itself a labour market, it is perhaps more correct to talk of the spatialization of information rather than the spatialization of labour. The results in this article echo the findings of Codagnone et al. (2016, p. 44) and Cullen and Farronato (2015). They also find that matching success depends on sellers and buyers living close to one another. They also find that the "natural efficiency" of online labour markets is very modest. The findings of this paper nonetheless differ from Cullen and Farronato (2015), because the TaskRabbit data they employ include data on price setting and auction mechanisms. In their study, it is possible to see the influence of price for matching supply and demand, while in this study matching happens on the basis of the proposals selfemployed workers provide. Through the price-setting mechanisms, the TaskRabbit platform achieves modest matching rates. In the TaskRabbit platform, it appears that the algorithm has more influence in suggesting sellers to customers. This is an indication that businesswise, TaskRabbit has more opportunities to optimize its "process of capitalization" than the lean platform of this study. A difference is also that TaskRabbit allows for standardization of tasks, which is not possible in the platform of this study.

\subsection{Theoretical and practical implications}

From a theoretical perspective, the main contribution of this study is to provide a deeper understanding of how a lean platform either enables or restricts customer acquisition, as an element of employment potential. The platform enables self-employed painters to acquire jobs, but it leaves price setting outside its scope. Following Srnicek (2017), this platform is clearly a lean platform, as it does not own much else than the data generated through the platform. However, it may be possible to see this platform as a different kind of lean platform, in that it makes visible the demand for jobs that are not necessarily "on-demand." This finding suits with the "weak ties" explanation of information availability through networks (Granovetter, 1973). This platform is, therefore, more a channel of customer acquisition than a form of outsourcing (Srnicek, 2017, p. 87), for self-employed workers. Although the data of this platform show a rather modest success rate for the status change, which enables the process of acquisition to commence, it does on the other hand provide a channel for true selfemployed workers to find jobs they may not have heard about otherwise. In a similar finding to Kingsley et al. (2015), the way the platform operates at the same time also provides a barrier to acquisition, since the platform user is dependent on consumer engagement with their proposal and furthermore he or she faces a fee in case of consumer interest for the proposal. Also, in this platform a form of power asymmetry can be observed.

In this platform, self-employed painters have a relatively passive role. A service request appears, they supply a proposal and then they must wait for the consumer response. The practical implication of this study is that the platform users should respond to requests that are quite close to them. The analysis highlights the importance of a good, professional
Employment potential of a lean platform 
IJM

42,2

proposal, although this could not be directly assessed. Therefore, the self-employed painters that use this kind of platform should approach customer acquisition with the same level of professionalism as acquisition outside the platform. It should be studied further what kind of proposal is the most efficient way to use the platform for customer acquisition.

\subsection{Limitations}

In contrast to Cullen and Farronato (2015), "matching" in this study is limited to a matching on mutual interest regarding the proposal the self-employed painter provided. The true matching rate is not known, since negotiations between customer and potential service provider take place outside the platform. The data more generally do not allow advanced analysis. Also, the motivations of these self-employed to be active on the platform are largely unknown. If a self-employed painter is active on the platform, it may signify he/she has a shortage of work. However, the underlying labour market tightness in this sector in 2017 would suggest this is not the core issue, which the low matching rate perhaps also exemplifies. Nonetheless, the data do also show that the painters use the platform relatively little, as measured by numbers of proposals per platform user. This indicates another limitation: these data do not tell anything about platform user exit, although the low success rate can assumed to be a factor. Furthermore, the lack of extensive review data of the platform users denies the possibility to study the influence of "customer engagement behavior" for employment possibilities (Van Doorn et al., 2010).

The data pose limits regarding methodology. Data that originate in a setting which is not designed for scientific inference complicate the possibilities to use "normal" analytical tools. The structure of the data of this study severely limited the options for analysis. The lack of a price-setting mechanism (contrary to the analysis in Cullen and Farranato, 2015) further complicated the possibilities for analysis.

\subsection{Further research}

Further research should focus on the experiences and motivations of platform workers. The data for the current study at most can hint at the beginning and end of engagement with the platform. Also, information about income through the platform would be useful to study. Another area of further research is the quality of the proposals to potential customers, which would be of broader interest for the study of self-employment. It would also be fruitful to further study the regional and local dimensions of customer acquisition through the platform, for instance, to study which self-employed painters often compete against each other. This information could be used to develop the platform's algorithm.

The development of new tools of analysis should be high on the agenda, since it is likely "unstructured" or "found" big data will be more often employed in the social sciences in the future. These kinds of data may provide interesting avenues for research of specific issues and cases. Digital data sources may enable social scientists to scrutinize parts of social reality that are often invisible, but influence people's behaviour.

\section{References}

Agrawal, A., Horton, J., Lacetera, N. and Lyons, E. (2015), "Digitization and the contract labor market: a research agenda", in Goldfarb, A., Greenstein, S.M. and Tucker, C.E. (Eds), Economic Analysis of the Digital Economy, University of Chicago Press, Chicago, pp. 219-250.

Autor, D.H. (2001), "Wiring the labor market”, The Journal of Economic Perspectives, Vol. 15 No. 1, pp. 25-40.

Autor, D. (2013), "The task approach to labor markets: an overview”, Journal of Labour Market Research, Vol. 46 No. 3, pp. 185-199. 
Azevedo, E.M. and Leshno, J.D. (2016), "A supply and demand framework for two-sided matching markets”, Journal of Political Economy, Vol. 124, No. 5, pp. 1235-1268.

Balaram, B., Warden, J. and Wallace-Stephens, F. (2017), Good Gigs, London, RSA, available at: https:// www.thersa.org/discover/publications-and-articles/reports/good-gigs-a-fairer-future-for-the-uksgig-economy (accessed 26 June 2019).

Belli, R.F., Traugott, M.W., Young, M. and McGonagle, K.A. (1999), "Reducing vote overreporting in surveys: social desirability, memory failure, and source monitoring", Public Opinion Quarterly, Vol. 63 No. 1, pp. 90-108.

Burrows, R. and Savage, M. (2014), "After the crisis? Big data and the methodological challenges of empirical sociology", Big Data and Society, Vol. 1 No. 1, pp. 1-6.

Cappelli, P. and Keller, J.R. (2013), "Classifying work in the new economy", Academy of Management Review, Vol. 38 No. 4, pp. 575-596.

Castells, M. (2010), The Rise of the Network Society, Wiley-Blackwell, Oxford.

Chen, H., Chiang, R.H. and Storey, V.C. (2012), "Business intelligence and analytics: from big data to big impact”, MIS Quarterly, Vol. 36 No. 4, pp. 1165-1188.

Codagnone, C., Abadie, F. and Biagi, F. (2016), "The future of work in the 'sharing economy'. Market efficiency and equitable opportunities or unfair precarisation?", Institutie for Prospective Technological Studies, JRC Science of Policy Report EUR 27913 EN, Edificio Expo, Seville, doi: 10.2139/ssrn.2784774 (accessed 30 January 2019).

Cullen, Z. and Farronato, C. (2015), "Outsourcing tasks online: matching supply and demand on peerto-peer internet platforms", available at: https://www.aeaweb.org/conference/2016/retrieve.php? pdfid=1469 (accessed 14 November 2019).

Cutolo, D. and Kenney, M. (2019), "Platform-dependent entrepreneurs: power asymmetries, risks, and strategies in the platform economy", available at SSRN: https://ssrn.com/abstract $=3372560$ (accessed 2 March 2020).

de Reuver, M., Sørensen, C. and Basole, R.C. (2018), "The digital platform: a research agenda”, Journal of Information Technology, Vol. 33 No. 2, pp. 124-135.

de Stefano, V. (2016), The Rise of the Just-In-Time Workforce: On-Demand Work, Crowdwork and Labour Protection in the Gig Economy, ILO, Geneva.

Dekker, F. (2018), "Werken in de klusseneconomie: een literatuurstudie", Beleid en Maatschappij, Vol. 45 No. 2, pp. 189-198.

Drahokoupil, J. and Fabo, B. (2016), "The platform economy and the disruption of the employment relationship", ETUI Research Paper-Policy Brief, available at: https://papers.ssrn.com/sol3/ papers.cfm?abstract_id=2809517 (accessed 26 June 2019).

EIB (2017), ”Trends op de Bouwarbeidsmarkt 2017-2022", available at: https://www.eib.nl/publicaties/ arbeidsmarkt/trends-op-de-bouwarbeidsmarkt-2017-2022/ (accessed 30 January 2019).

EURES (2019), "Netherlands - national level", available at: https:/ec.europa.eu/eures/main.jsp? catId $=2588 \&$ acro $=$ lmi\&lang $=$ en $\&$ countryId $=$ NL.

Evans, D.S. (2003), "Some empirical aspects of multi-sided platform industries", Review of Network Economics, Vol. 2 No. 3, pp. 191-209.

Evans, D. and Schmalensee, R. ( 2007), "The industrial organization of markets with two-sided platforms", CPI Journal, Competition Policy International Vol. 3, pp. 1-36, available at: https:// www.nber.org/papers/w11603.

Evans, P.B. and Wurster, T.S. (1999), Blown to Bits: How the Economics of Information Transforms Strategy, Harvard Business School, Boston.

Farrell, D., Greig, F. and Hamoudi, A. (2018), The Online Platform Economy in 2018. Driver, Workers, Sellers, and Lessors, JPMorgan Chase Institute, New York.

Field, A., Miles, J. and Field, Z. (2012), Discovering Statistics Using R, Sage Publications, London.
Employment potential of a lean platform 
IJM

42,2

\section{0}

Fieseler, C., Bucher, E. and Hoffmann, C.P. (2019), "nfairness by design? The perceived fairness of digital labor on crowdworking platforms", Journal of Business Ethics, Vol. 156 No. 4, pp. 987-1005.

Florisson, R. and Mandl, I. (2018), "Platform work: types and implications for work and employment literature review", Eurofound Working Paper WPEF18004, available at: https://www. eurofound.europa.eu/data/platform-economy/records/platform-work-types-and-implications-forwork-and-employment-literature-review (accessed 21 June 2019).

Frenken, K. and Straathof, B. (2015), "Online platforms op (en in plaats van) de arbeidsmarkt", in Koninklijke Vereniging voor Staathuishoudkunde (Ed.), Preadviezen van de Koninklijke Vereniging voor Staatshuishoudkunde. De Match tussen Mens en Machine, pp. 163-174.

Friedman, G. (2014), "Workers without employers: shadow corporations and the rise of the gig economy", Review of Keynesian Economics, Vol. 2 No 2, pp. 171-188.

Gandini, A., Pais, I. and Beraldo, D. (2016), "Reputation and trust on online labour markets: the reputation economy of Elance", Work Organisation, Labour and Globalisation, Vol. 10 No. 1, pp. 27-43.

Gandomi, A. and Haider, M. (2015), "Beyond the hype: big data concepts, methods, and analytics", International Journal of Information Management, Vol. 35 No. 2, pp. 137-144.

Granovetter, M.S. (1973), "The strength of weak ties", American Journal of Sociology, Vol. 78, pp. $1360-1380$.

Kalleberg, A. and Dunn, M. (2016), “Good jobs, bad jobs in the gig economy”, Perspectives on Work, available at: http://www.lerachapters.org/OJS/ojs-2.4.4-1/index.php/LERAMR/article/download/ 3093/3068 (accessed 14 November 2019).

Karpatne, A., Atluri, G., Faghmous, J.H., Steinbach, M., Banerjee, A., Ganguly, A. and Kumar, V. (2017), "Theory-guided data science: a new paradigm for scientific discovery from data", IEEE Transactions on Knowledge and Data Engineering, Vol. 29 No. 10, pp. 2318-2331.

Kenney, M. and Zysman, J. (2016), "The rise of the platform economy", Issues in Science and Technology, Vol. XXXII No. 3, available at: http://issues.org/32-3/the-rise-of-the-platformeconomy/ (accessed 21 June 2019).

Kingsley, S.C., Gray, M.L. and Suri, S. (2015), “Accounting for market frictions and power asymmetries in online labor markets", Policy and Internet, Vol. 7 No. 4, pp. 383-400.

Kitchin, R. (2014), "Big Data, new epistemologies and paradigm shifts", Big Data and Society, Vol. 1 No. 1 , pp. 1-12.

Langley, P. and Leyshon, A. (2017), "Platform capitalism: the intermediation and capitalisation of digital economic circulation", Finance and Society, Vol. 3 No. 1, pp. 11-31.

Rochet, J.-C. and Tirole, J. (2003), "Platform competition in two-sided markets", Journal of the European Economic Association, Vol. 1 No. 4, pp. 990-1029.

Schor, J.B. and Attwood-Charles, W. (2017), "The "sharing" economy: labor, inequality, and social connection on for-profit platforms", Sociology Compass, Vol. 11 No. 8, pp. 1-16.

Schor, J.B. and Fitzmaurice, C.J. (2015), "Chapter 26. Collaborating and connecting: the emergence of the sharing economy", in Reisch, L. and Thogersen, J. (Eds), Handbook of Research on Sustainable Consumption, Edgar Elgar, Massachusetts, pp. 410-425.

Seyfang, G. (2004), "Working outside the box: community currencies, time banks and social inclusion", Journal of Social Policy, Vol. 33 No. 1, pp. 49-71.

Srnicek, N. (2017), Platform Capitalism, John Wiley \& Sons, Oxford.

Stanford, J. (2017), "The resurgence of gig work: historical and theoretical perspectives", Economic and Labour Relations Review, Vol. 28 No. 3, pp. 382-401.

ter Weel, B., van der Werff, S., Bennaars, H., Scholte, R., Fijnje, J., Westerveld, M. and Mertens, T. (2018), De opkomst en groei van de kluseconomie Nederland, (SEO-rapport; No. 2018-30), SEO Economisch Onderzoek, Amsterdam. 
Tinati, R., Halford, S., Carr, L. and Pope, C. (2014), "Big data: methodological challenges and approaches for sociological analysis”, Sociology, Vol. 48 No. 4, pp. 663-681.

Urzì Brancati, C., Pesole, A. and Fernández-Macías, E. (2020), "New evidence on platform workers in Europe. Results from the second COLLEEM survey", EUR 29958 EN, Publications Office of the European Union, Luxembourg.

UWV (2018), "Bouw: factsheet arbeidsmarkt", available at: https:/www.uwv.nl/overuwv/kenniscijfers-en-onderzoek/arbeidsmarktinformatie/factsheet-bouw.aspx, (accessed 30 January 2019).

Van Doorn, J., Lemon, K., Mittal, V., Nass, S., Pick, D., Pirner, P. and Verhoef, P. (2010), "Customer engagement behavior: theoretical foundations and research directions", Journal of Service Research, Vol. 13 No. 3, pp. 253-266.

\section{Further reading}

van Eck, J.R. and Snellen, D. (2006), "Is the Randstad a city network? Evidence from commuting patterns", European Transport Conference, Vol. 18, September, available at: http://citeseerx.ist.psu. edu/viewdoc/download?doi=10.1.1.453.8363\&rep=rep1\&type=pdf (accessed 30 January 2019).

Weil, D. (2014), The Fissured Workplace, Harvard University Press, Harvard.

\section{Corresponding author}

Paul Jonker-Hoffrén can be contacted at: paul.jonker-hoffren@tuni.fi
Employment potential of a lean platform

For instructions on how to order reprints of this article, please visit our website:

www.emeraldgrouppublishing.com/licensing/reprints.htm

Or contact us for further details: permissions@emeraldinsight.com 